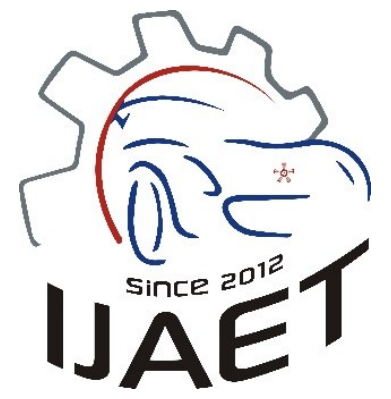

e-ISSN: 2146 - 9067

International Journal of Automotive

Engineering and Technologies

journal homepage:

https://dergipark.org.tr/en/pub/ijaet

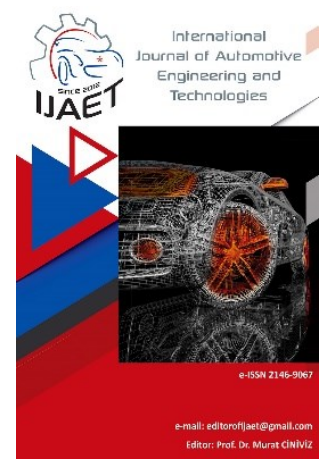

Original Research Article

\title{
Prediction of spark ignition engine performance responses fueled with fusel oil/gasoline blends by artificial neural network
}

\author{
Samet Uslu ${ }^{1 *}$, Süleyman Simsek ${ }^{2}$ \\ ${ }^{1}$ Karabuk University, Department of Mechanical Engineering, Karabuk, Turkey. \\ 2 İstanbul Aydın University, Department of Mechanical Engineering, İstanbul, Turkey.
}

\section{ARTICLE INFO}

Orcid Numbers

1. 0000-0001-9118-5108

2. $0000-0002-0593-8036$

Doi: $10.18245 /$ ijaet.807339

* Corresponding author sametuslu@karabuk.edu.tr

Received: Oct 07, 2020

Accepted: Mar 11, 2021

Published: Jun 30, 2021

Published by Editorial Board Members of IJAET

(C) This article is distributed by Turk Journal Park System under the CC 4.0 terms and conditions.

\begin{abstract}
In the present study, the performance parameters of a single-cylinder, air-cooled spark ignition (SI) engine using fusel oil-gasoline fuel blends were predicted by artificial neural network (ANN). The SI engine was operated with gasoline/fusel oil (10\% and 20\%) blends at different engine load (1000, 2000, 3000, 4000, 5000, $6000,7000$ and $8000 \mathrm{Watt})$ and compression ratios $(8.00,9.12$ and 10.07) to obtain data essential to create the ANN model. In the constructed ANN model, brake thermal efficiency (BTE) and brake specific fuel consumption (BSFC) are chosen as output parameters, while engine load, compression ratio $(\mathrm{CR})$ and fusel oil ratio are chosen as input factors. $75 \%$ of the test results were employed to train the ANN. The performance of ANN model was determined by comparing it with the data produced from the part not used for training. According to the found data, ANN model estimated engine performance parameters such as BTE and BSFC by an overall regression coefficient (R) at 0.99384 . Simultaneously, mean absolute percentage error (MAPE) were found as $5.027 \%$ and $7.847 \%$ for BTE and BSFC, respectively. When ANN results and experimental results are compared for BTE and BSFC responses, it is determined that ANN results are close to experimental results with an error rate of less than $5 \%$.

Keywords: Fusel oil, artificial neural network, performance, spark ignition engine
\end{abstract}

\section{Introduction}

The fact that fossil fuels are constantly and rapidly decreasing with the increasing population, together with increasing fuel costs and environmental pollution, have made it essential to find environmentally friendly, cheap and renewable fuels for spark ignition engines [1-3]. Recently, biofuels with higher thermal efficiency and lower emissions compared to fossil fuels have been remarkable in the search for alternative fuels [4]. Among the biofuels, alcohols such as heptanol, ethanol, butanol and methanol are widely used in SI engines due to both the higher-octane number and higher oxygen contain in their structure $[5,6]$. Although almost most alcohols can be used in SI engines, long chain alcohols with high carbon can be more efficient in SI engines due to their better combustion properties and higher-octane numbers [7, 8]. Fusel oil, which can be obtained by fermentation during the distillation process in ethyl alcohol production, also falls into the category of long chain alcohol [9]. Fusel oil includes alcohol types such as iamyl alcohol, i-butyl alcohol and ethyl alcohol 
[10-13]. The oxygen content and octane number of fusel oil is higher than fossil fuels, just like alcohol fuels, thanks to the high percentage of alcohols it contains [14]. The utilization of an unused material as an alternative fuel has been very important in recent years. Since it is dangerous to the ecosystem, waste materials must be disposed of and the budgets allocated for the disposal of these unused materials can be quite high. Hence, it would be more efficient and beneficial to spend it for use as fuel in internal combustion engines (ICEs), rather than spending money on disposal of such unused or waste materials. From this point on, it is thought that using fusel oil in SI engines by mixing with gasoline in certain proportions will be more beneficial than disposal. Based on this idea, the effects of using fusel oil in BA engines have been studied for years $[9,12,13,15]$.

Since the experiments to measure and determine the performance responses of ICEs are both long and costly, applications and programs that can predict these performance responses are preferred with developing technology and software knowledge $[16,17]$. Therefore, instead of running all the experiments, researchers apply predictive applications to achieve near efficiency with fewer experiments. ANN technique is an application that can be used to obtain similar results with fewer experiments [18]. The ANN method can be used to overcome the deficiencies in cases where traditional methods used for years in the field of engineering are inadequate and cannot produce high accuracy results. The predictive skill of ANN is provided by training with test data and subsequent confirmation. If another data is accessible, ANN can relearn to enhance performance [19]. In latest times, significant success has been achieved in the applicability of ANN technique for SI engines and a significant number of studies have been conducted. Taghavi et al. [20] aimed to predict the combustion start of a homogeneous charge compression ignition engine with a multi-input single output ANN model, which they trained using experimental data from a single cylinder Ricardo engine. Based on the low error rates they obtained by comparing the results of ANN with experimental data, they stated that ANN is a powerful approach to predict the combustion start of an engine with homogeneous charge compression ignition. Mehra et al. [21] in their study using ANN, aimed to predict the performance and emission characteristics of a turbocharged BA engine fed with various hydrogen-enriched compressed natural gas mixtures. They stated that they obtained high $\mathrm{R}^{2}$ values and low error rates and that the study sheds light on the fact that ANN can be used to minimize the performance and emission characteristics of hydrogen added engines. Kiani et al. [22] established an ANN model to predict some performance and emission parameters of a four-cylinder spark ignition engine. They stated that according to the results obtained, generally high $\mathrm{R}^{2}$ values were obtained and thus ANN provided results with high accuracy. In addition, they stated that their work would shed light on the next studies to reduce the number of experiments.

In the above-mentioned studies, the effects of fusel oil / gasoline fuel mixtures on the performance of SI engines were investigated and predicted. On the other hand, sufficient research has not been done on the capability of ANN to predict input-output parameters in spark ignition engines using fusel oil / gasoline fuel mixtures. Present research has been conducted to contribute to the literature in this sense. In this study, while BTE and BSFC were chosen as output parameters, engine load, CR and fusel oil ratio were chosen as input parameters. The ANN method was used as a suitable step to estimate the performance of fusel oil / gasoline blends in order to reduce the number of tests of a spark ignition engine.

\section{Material and Method}

Experiments in this study were carried out on an air cooled, single-cylinder and four-stroke SI engine whose characteristics are displayed in Table 1. The experimental apparatus shown in Figure 1 contains of engine, generator, digital scales, and engine load components. In this study, a Honda GX390 single cylinder fourstroke gasoline engine was used and a loading unit consisting of halogen bulbs was used to load the engine. Ender brand SWOCK YP20002 model electronic digital scale was used to measure the fuel consumption of the experimental engine, and a Delta SW 305 brand stopwatch was used for the measurement of fuel consumption duration. 


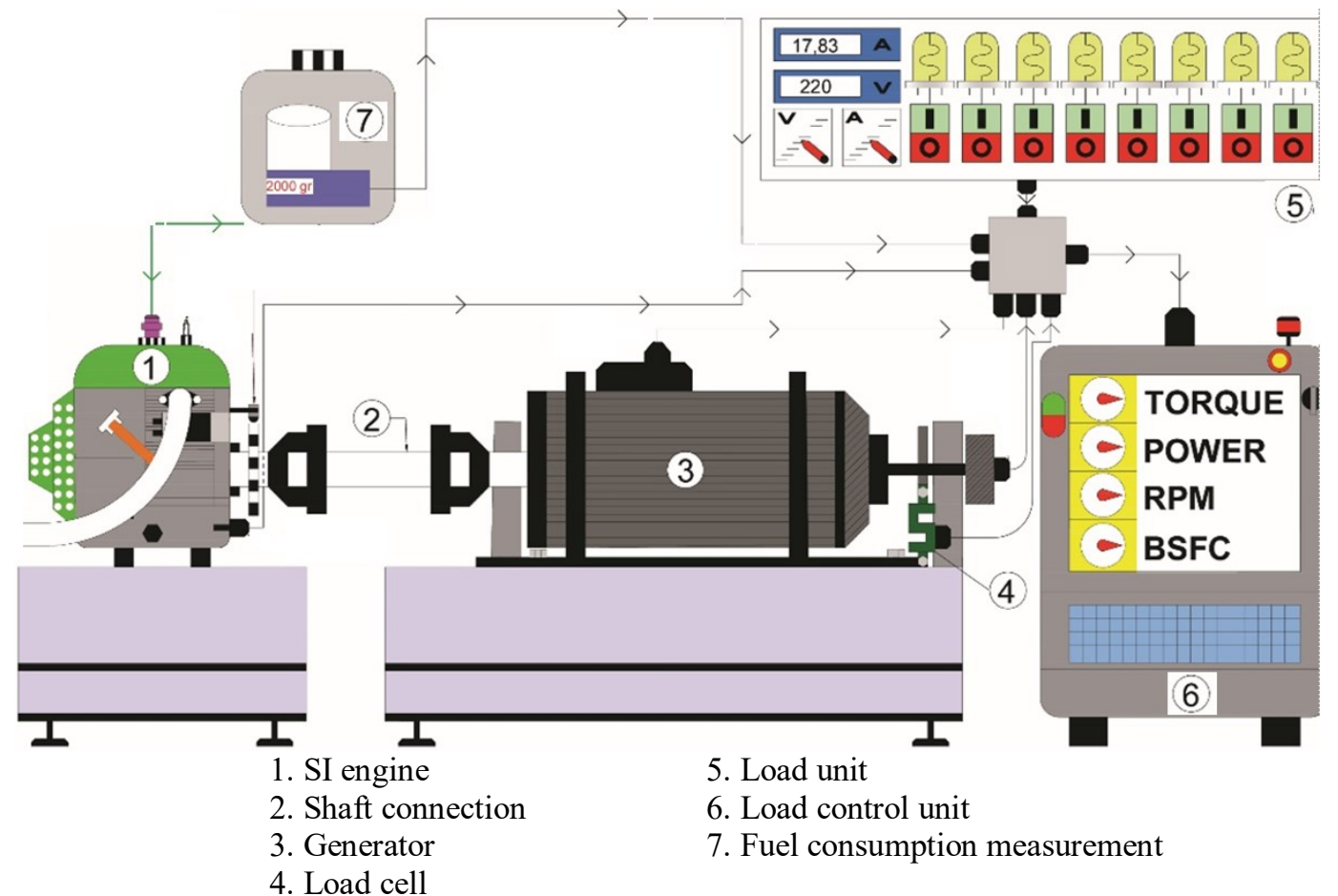

Figure 1. Experimental setup

In present research, experiments were carried out with different fusel oil ratios $(10 \%$ and $20 \%$ ), different $\mathrm{CR}$ values $(8.00,9.12$ and 10.07), and the generator and engine were loaded at different resistance values (1000, 2000, 3000, 4000, 5000, 6000, 7000 and 8000 $\mathrm{W})$ at constant engine speed as $1700 \mathrm{rpm}$.

Table 1. Properties of engine

\begin{tabular}{|c|c|}
\hline \multicolumn{2}{|l|}{ Engine Properties } \\
\hline Trademark & Honda GX390 \\
\hline Type & $\begin{array}{l}\text { Four times, single } \\
\text { cylinder }\end{array}$ \\
\hline Compression ratio & $8.0: 1$ \\
\hline Maximum horsepower & $11.8 \mathrm{hp}$ \\
\hline Overall volume & $389 \mathrm{~cm}^{3}$ \\
\hline $\begin{array}{l}\text { Maximum engine } \\
\text { speed }\end{array}$ & $3600 \mathrm{rpm}$ \\
\hline Cooling system & Air cooled \\
\hline \multicolumn{2}{|l|}{ Generator Properties } \\
\hline Brand & Honda HK $550 \mathrm{M} / \mathrm{MS}$ \\
\hline Max. power & $5.5 \mathrm{~kW}$ \\
\hline
\end{tabular}

For the CR to be variable in an engine, either the engine must be constructed with the adjustable $\mathrm{CR}$ while it is being manufactured, or several modifications must be made in the current engine. In this study, the $\mathrm{CR}$ is changed by changing the cylinder top cover. With the original CR of 8 , two separate covers identical to the original cylinder top cover of the engine were grinded $0.80 \mathrm{~mm}$ and $1.00 \mathrm{~mm}$, respectively. Thus, CR values were increased by reducing the engine cylinder volume and CRs of
9.12 and 10.07 were obtained, respectively. The cylinder top covers mounted on the engine before the experiment.

The major assets of the test fuels are presented in Table 2. The values (torque and fuel consumption) required to calculate the performance values BTE and BSFC were measured after the steady operating conditions. In order to minimize measurement errors, each of the experiments performed at least three times and the results obtained were averaged.

Table 2. Fuel properties

\begin{tabular}{|c|c|c|c|}
\hline Properties & Gasoline & F10 & F20 \\
\hline Density $\left(\mathrm{kg} / \mathrm{m}^{3}\right)$ & 721.79 & 726.03 & 735.13 \\
\hline $\begin{array}{l}\text { Lower heating } \\
\text { value }(\mathrm{kJ} / \mathrm{kg})\end{array}$ & 44000 & 42449 & 41319 \\
\hline $\begin{array}{l}\text { Research } \\
\text { Octane Number }\end{array}$ & 95.60 & 97.80 & 97.84 \\
\hline $\begin{array}{l}\text { Motor Octane } \\
\text { Number }\end{array}$ & 85.8 & 87.08 & 87.12 \\
\hline
\end{tabular}

Since the experimental study results include irregularities and uncertainties arising from environmental conditions, regulations and test device sensitivities, uncertainty analysis is required to ensure and prove the accuracy of the results. In this study, the square root technique proposed by Holman for the calculation of uncertainties was preferred and the equation used is given below with Eq. 1 [23]; 


$$
\begin{gathered}
w_{R}=\left[\left(\frac{\partial R}{\partial x_{1}} w_{1}\right)^{2}+\left(\frac{\partial R}{\partial x_{2}} w_{2}\right)^{2}+\cdots\right. \\
\left.+\left(\frac{\partial R}{\partial x_{n}} w_{n}\right)^{2}\right]^{1 / 2}
\end{gathered}
$$

Where,

$>R$ : related component and a function of independent factors,

$>x_{1}, x_{2}, \ldots, x_{n}$ : independent factors,

$>w_{R}$ : uncertainty value of the responses,

$>w_{1}, w_{2}, \ldots, w_{n}$ : uncertainties of the independent factors.

The outcomes achieved from the uncertainty analysis of various factors are shown in Table 3. The total uncertainty analysis was determined as below;

Overall uncertainty

$=$ square root of $[\text { (uncertainty of load })^{2}$

$+(\text { uncertainty of } B T E)^{2}$

$\left.+(\text { uncertainty of } B S F C)^{2}\right]$

$=$ square root of $\left[(0.88)^{2}+(1.21)^{2}+(0.73)^{2}\right]$

$$
= \pm 1.665 \%
$$

Table 3. The uncertainties of the measured and calculated parameters

\begin{tabular}{cccc}
\hline Parameter & $\begin{array}{c}\text { Engine } \\
\text { Load }\end{array}$ & $\begin{array}{c}\text { Brake } \\
\text { thermal } \\
\text { efficiency }\end{array}$ & $\begin{array}{c}\text { Mass of fuel } \\
\text { consumption }\end{array}$ \\
\hline $\begin{array}{c}\text { Measurement } \\
\text { range }\end{array}$ & $0-8 \mathrm{~kW}$ & - & $0-20 \mathrm{~kg}$ \\
$\begin{array}{c}\text { Accuracy } \\
\text { Uncertainty } \\
(\%)\end{array}$ & $1 \mathrm{Watt}$ & - & $0.01 \mathrm{~g}$ \\
\hline 0.88 & \pm 1.21 & \pm 0.73 \\
\hline
\end{tabular}

In this ANN study, engine load, fusel oil ratio and CR were selected as input parameters, while BTE and BSFC output parameters were chosen as parameters to be estimated. The representation of the established ANN is shown in Figure 2. In this ANN model, the feed forward back propagation network type, which is widely used to explain the complex problems in system modeling and description, was chosen [24]. In addition, the Levenberg-Marquardt (Trainlm) training function, which is used in estimations, was preferred because it generally exhibits high performance rates [25]. As the transfer function, the logistic sigmoid (logsig) function was preferred because it provides better results compared to other functions in formulating the suitable model [26] - [29]. In order to measure the prediction success of the ANN models, R, MAPE and mean squares error (MSE) were used. The next equations are utilized for assessment [17]:

$$
\begin{aligned}
& R=\sqrt{1-\left(\frac{\sum_{i=1}^{n}\left(t_{i}-o_{i}\right)^{2}}{\sum_{i=1}^{n}\left(o_{i}\right)^{2}}\right)} \\
& M S E=\sqrt{1-\left(\frac{\sum_{i=1}^{n}\left(t_{i}-o_{i}\right)^{2}}{\sum_{i=1}^{n}\left(o_{i}\right)^{2}}\right)} \\
& M A P E=\frac{1}{n} \sum_{i=1}^{n}\left|100 \frac{t_{i}-o_{i}}{t_{i}}\right|
\end{aligned}
$$

Where,
$>n$ : number of points
$>$ : estimated output data independent factors,
$>t$ : actual output

\section{INPUT HIDDEN OUTPUT LAYER LAYER LAYER}

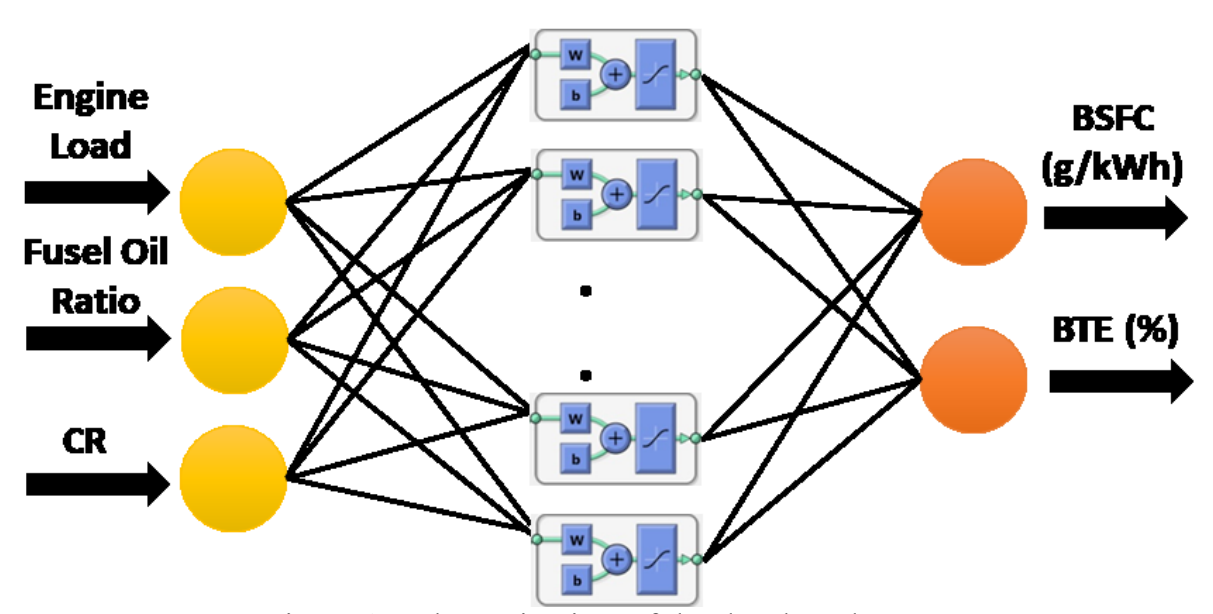

Figure 2. Schematic view of the developed ANN 
Prediction using ANN generally involves three sequential steps: the modeling, learning, or training phase, and the testing phase [30]. During the training phase, the network is trained to create an output estimation based on input data. During the test phase, experimental data are compared with the estimated data. Network training is interrupted when the test error achieves the desired tolerance. The flow diagram of ANN is presented in Figure 3. In first step, CR, fusel oil percentage and engine load are entered as input data to ANN. About $75 \%$ of the total experimental data were chosen for training and $25 \%$ for testing. In second step, ANN has been trained many times to reach the best trained ANN by analyzing verification, training and test graphs. Finally, in third step, the final control of ANN has been done.

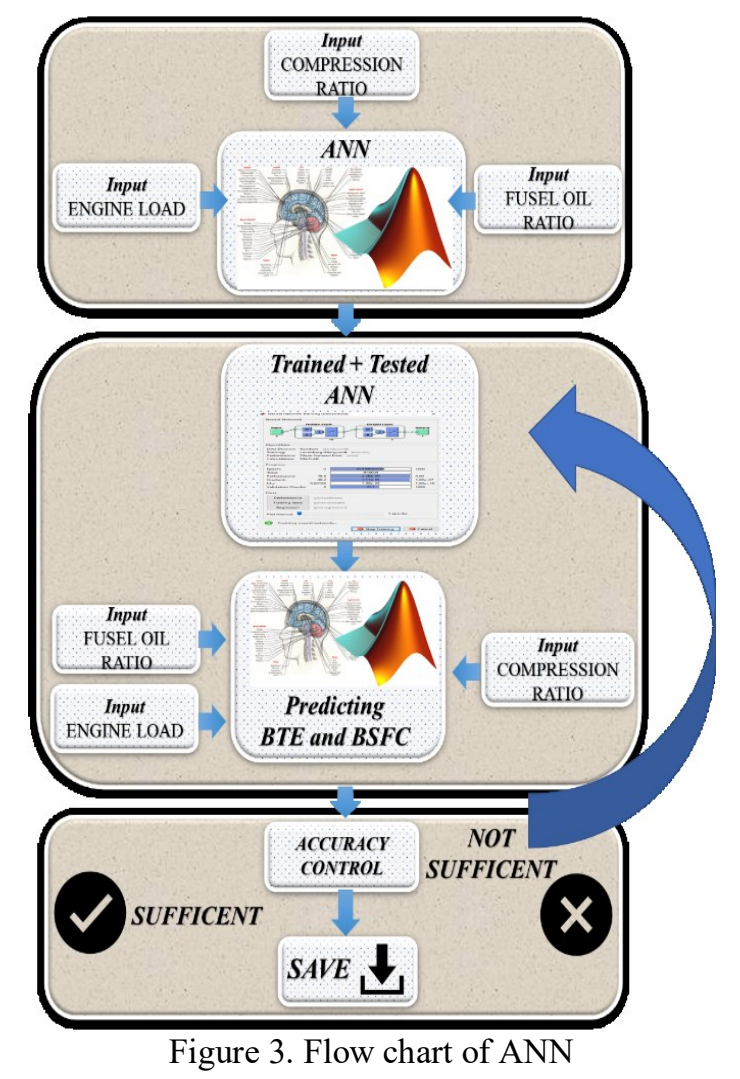

3. Result and Discussion

\subsection{Experimental results}

In this section, results obtained from the experiments conducted to examine the effects of selected factors on BTE and BSFC are given. BTE and BSFC results for all test fuels at different compression ratio under various engine load are shown in Figure 4 and Figure 4, respectively. It can be observed from the BTE graphs that for all test fuels, BTE increases with the compression ratio increasing from 8 to 9.12 and decreases again at the compression ratio of 10.07. CR is one of the most important parameters affecting engine efficiency. However, the risk of knocking in SI engines is a problem that limits $\mathrm{CR}$. The higher the $\mathrm{CR}$, the higher the efficiency until knock occurs. In this study, the maximum BTE values were obtained at $9.12 \mathrm{CR}$ value. Further increasing the compression ratio caused knock and thus the BTE tended to decrease. In addition, it was concluded that BTE increased with the increasing rate of fusel oil in general. The highoctane number of fusel oil compared to gasoline and its oxygen content are the main reasons for the increase of BTE. There are some studies in which similar results have been obtained showing that BTE increases with increasing fusel oil ratio [31,32]. The energy content of a fuel has a direct effect on the BSFC, which expresses the ratio between fuel mass consumption and brake power [33]. BSFC is one of the important parameters that show the performance of fuels when the engine is running on different fuels. It is an indicator of how efficiently the engine produces work with different fuels. When examined in terms of BSFC, as the ratio of fusel oil increased, the BSFC also increased. In order to reach the power provided by gasoline fuel, more fuel should be consumed with fuels containing fusel oil. The low calorific value of fusel oil has led to an increase in BSFC. Similar results are found in studies conducted with fusel oil in the literature [34,35]. Since CR increases efficiency, BSFC decreases with the increase of CR. Since CR increases efficiency, BSFC decreases with the increase of CR. With the increase of CR from 8.00 to 9.12 , the BSFC decreased and with the increase of CR to 10.07, it started to increase again. This was due to the decrease in BTE due to the knock that occurred with the CR coming to 10.07 .

\subsection{ANN modeling}

In this study, an ANN is designed using the data obtained from experiments to estimate the performance parameters of a spark ignition engine. Engine load, fusel oil ratio and CR are selected as input parameters, while BTE and BSFC are selected as output parameters. 


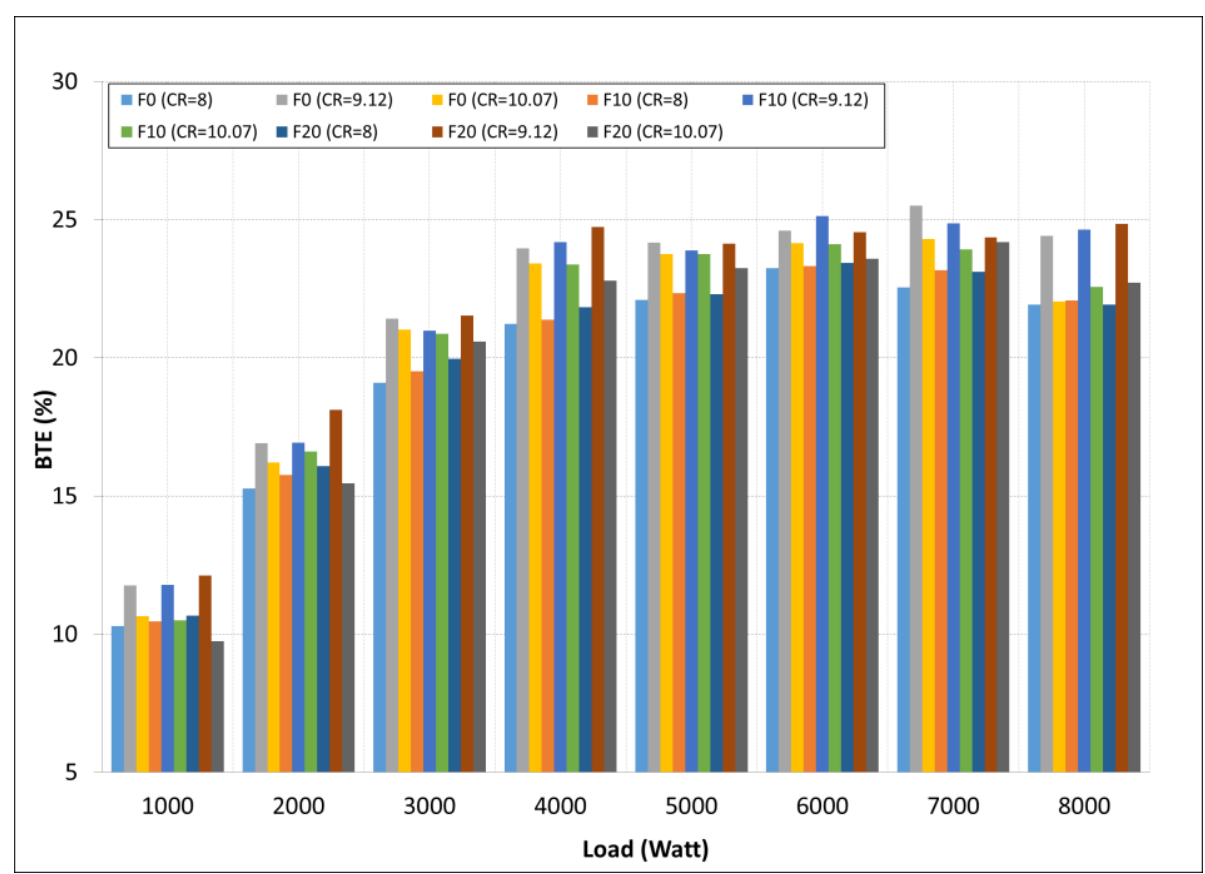

Figure 4. BTE results for all test fuels at different compression ratio under various engine load

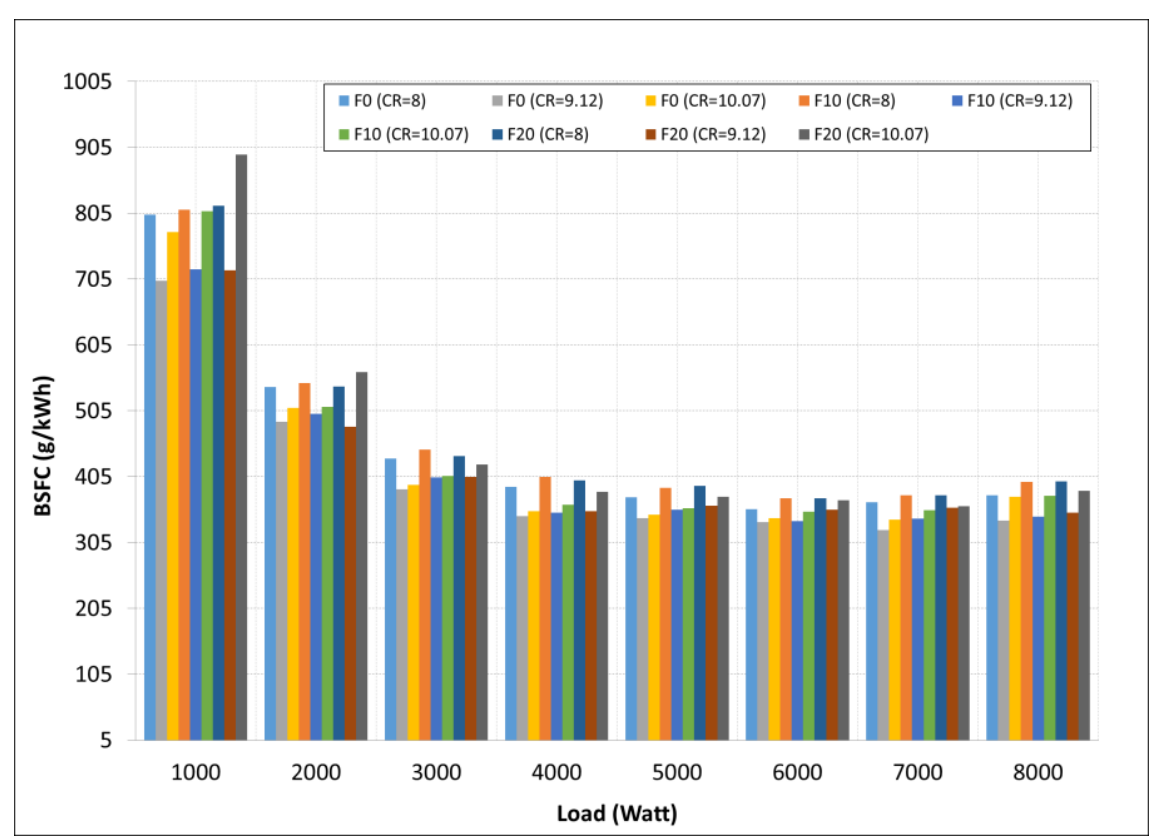

Figure5. BSFC results for all test fuels at different compression ratio under various engine load

The TRAINLM with one hidden layer is tested by differing number of neurons from two to fifteen for logsig transfer function. The outcomes achieved from several number of neurons are tabulated in Table 4. The maximum $\mathrm{R}$ and minimum MSE and MAPE are obtained with a network that is a hidden layer with 10 neurons. Therefore, (3-10-2) topology is observed to be the ideal for predicting the inputoutput parameters wherein three neurons for input layer, ten neurons for hidden layer and two neurons for output layer.

he general regression plot taken from ANN in this study is shown in Figure 6. $\mathrm{R}$ values for training, validation and testing were 0.99644, 0.99888 and 0.98462 , respectively. The total $\mathrm{R}$ value was determined as 0.99384 . The fact that $R$ values are near to 1 is a sign of its high precision. It was noticed that the $\mathrm{R}$ values obtained from this study were so close to 1 . Therefore, it showed good accuracy in modeling ANN performance parameters.

For the performance parameters of the spark ignition engine tested, the predictions made by ANN showed great statistical performance. The charts found by comparing the experimental findings and the results obtained from the ANN estimations indicate that a single cylinder spark 
ignition engine using fusel oil/gasoline fuel mixtures can be simulated precisely with ANN. The comparison table is shown in Table 6 where the test and ANN results for the 12 trials for BTE and BSFC are given together with the error rates. It can be seen from the table that the error rates found are generally acceptable. The graphics comparing the ANN outcomes and the experimental outcomes for BTE and BSFC are displayed in Figure 7. While the R value found for BTE was found to be 0.9929, it was determined as 0.9953 for BSFC. In addition, MAPE and MSE values were found to be $5.027 \%$ and $0.325 \%$ for BTE, respectively. These values were found to be $7.847 \%$ and $14.845 \mathrm{~g} / \mathrm{kWh}$ for the BSFC, respectively.

By looking at the $\mathrm{R}$ values and error amounts, it can be said that the estimates made for engine performance parameters are within acceptable limits.

Table 4. Results of various number of neurons

\begin{tabular}{|c|c|c|c|c|c|c|}
\hline \multirow{2}{*}{$\begin{array}{l}\text { Number of } \\
\text { neurons }\end{array}$} & \multicolumn{4}{|c|}{ Regression coefficient (R) } & \multirow{2}{*}{ MSE } & \multirow{2}{*}{ MAPE $(\%)$} \\
\hline & Training & Validation & Testing & Overall & & \\
\hline 2 & 0.98887 & 0.99417 & 0.98791 & 0.98992 & 0.001118 & 4.027 \\
\hline 3 & 0.98711 & 0.99606 & 0.99556 & 0.98987 & 0.001323 & 4.467 \\
\hline 4 & 0.98338 & 0.99719 & 0.99862 & 0.98977 & 0.001842 & 4.704 \\
\hline 5 & 0.98280 & 0.99723 & 0.97788 & 0.98774 & 0.001922 & 4.983 \\
\hline 6 & 0.96387 & 0.99448 & 0.99962 & 0.97669 & 0.002912 & 7.682 \\
\hline 7 & 0.97694 & 0.99938 & 0.98919 & 0.97896 & 0.002521 & 6.865 \\
\hline 8 & 0.97883 & 0.99328 & 0.98565 & 0.98592 & 0.00242 & 5.400 \\
\hline 9 & 0.97123 & 0.99488 & 0.99978 & 0.97249 & 0.003778 & 7.307 \\
\hline 10 & 0.99644 & 0.99888 & 0.98462 & 0.99384 & 0.000196 & 2.054 \\
\hline 11 & 0.99667 & 0.93736 & 0.94877 & 0.96703 & 0.004322 & 8.958 \\
\hline 12 & 0.95337 & 0.99575 & 0.99031 & 0.96718 & 0.004104 & 8.923 \\
\hline 13 & 0.93121 & 0.97417 & 0.91461 & 0.93431 & 0.004749 & 10.801 \\
\hline 14 & 0.99044 & 0.92105 & 0.98744 & 0.97452 & 0.002969 & 7.520 \\
\hline 15 & 0.99519 & 0.99779 & 0.98118 & 0.99256 & 0.000403 & 2.362 \\
\hline
\end{tabular}

Table 5. Weight and bias values of the ANN model

\begin{tabular}{ccccc}
\hline & \multicolumn{5}{c}{$w_{3}$} & $b$ \\
\cline { 2 - 5 } & $w_{1}$ & $w_{2}$ & 0.30925 & 3.8744 \\
1 & -0.38736 & 3.9194 & -3.9668 & 6.6427 \\
2 & -0.29561 & -3.4537 & -2.5822 & 4.719 \\
3 & -3.0656 & -1.0412 & -5.9878 & -1.0337 \\
4 & 0.17617 & 1.1947 & -4.0876 & 2.062 \\
5 & -3.733 & 2.4845 & -5.4706 & -1.1524 \\
6 & -3.6584 & -0.39508 & 4.5397 & 0.56994 \\
7 & -3.8923 & 0.051568 & -4.1423 & 4.4296 \\
8 & 3.3347 & -1.2623 & -5.1698 & 6.8069 \\
9 & 2.5085 & -3.2776 & -7.6061 & -2.0707 \\
10 & -1.217 & -0.87815 &
\end{tabular}

Table 6. Comparison of test and ANN results for BTE and BSFC

\begin{tabular}{|c|c|c|c|c|c|c|c|c|c|}
\hline \multirow{3}{*}{$\begin{array}{c}\text { Trial } \\
\text { No. }\end{array}$} & \multirow{2}{*}{\multicolumn{3}{|c|}{ Input }} & \multicolumn{6}{|c|}{ Responses } \\
\hline & & & & \multicolumn{3}{|c|}{ BTE (\%) } & \multicolumn{3}{|c|}{ BSFC (g/kWh) } \\
\hline & $\begin{array}{l}\text { Engine } \\
\text { Load }\end{array}$ & $\begin{array}{c}\text { Fusel Oil } \\
\text { Ratio }\end{array}$ & CR & Test & $\mathbf{A N N}$ & $\begin{array}{c}\text { Error } \\
(\%)\end{array}$ & Test & $\mathbf{A N N}$ & $\begin{array}{c}\text { Error } \\
(\%)\end{array}$ \\
\hline 1 & 3000 & 10 & 8 & 20.624 & 19.511 & 5.703 & 415.486 & 446.409 & 6.927 \\
\hline 2 & 7000 & 10 & 8 & 23.280 & 23.170 & 0.476 & 365.460 & 376.787 & 3.006 \\
\hline 3 & 2000 & 20 & 8 & 14.940 & 16.082 & 7.100 & 494.302 & 541.771 & 8.762 \\
\hline 4 & 5000 & 20 & 8 & 22.864 & 22.294 & 2.553 & 364.775 & 390.800 & 6.659 \\
\hline 5 & 1000 & 10 & 9.12 & 10.643 & 11.777 & 9.626 & 714.455 & 720.118 & 0.786 \\
\hline 6 & 4000 & 10 & 9.12 & 22.608 & 24.191 & 6.545 & 387.520 & 350.563 & 10.542 \\
\hline 7 & 1000 & 20 & 9.12 & 11.831 & 12.122 & 2.406 & 759.861 & 718.732 & 5.722 \\
\hline 8 & 6000 & 20 & 9.12 & 24.323 & 24.536 & 0.869 & 337.834 & 355.101 & 4.862 \\
\hline 9 & 2000 & 10 & 10.07 & 14.952 & 16.607 & 9.967 & 580.179 & 510.660 & 13.614 \\
\hline 10 & 5000 & 10 & 10.07 & 24.208 & 23.753 & 1.916 & 356.899 & 357.031 & 0.037 \\
\hline 11 & 3000 & 20 & 10.07 & 19.108 & 20.580 & 7.153 & 398.934 & 423.360 & 5.770 \\
\hline 12 & 7000 & 20 & 10.07 & 22.655 & 24.186 & 6.330 & 371.194 & 360.236 & 3.042 \\
\hline
\end{tabular}



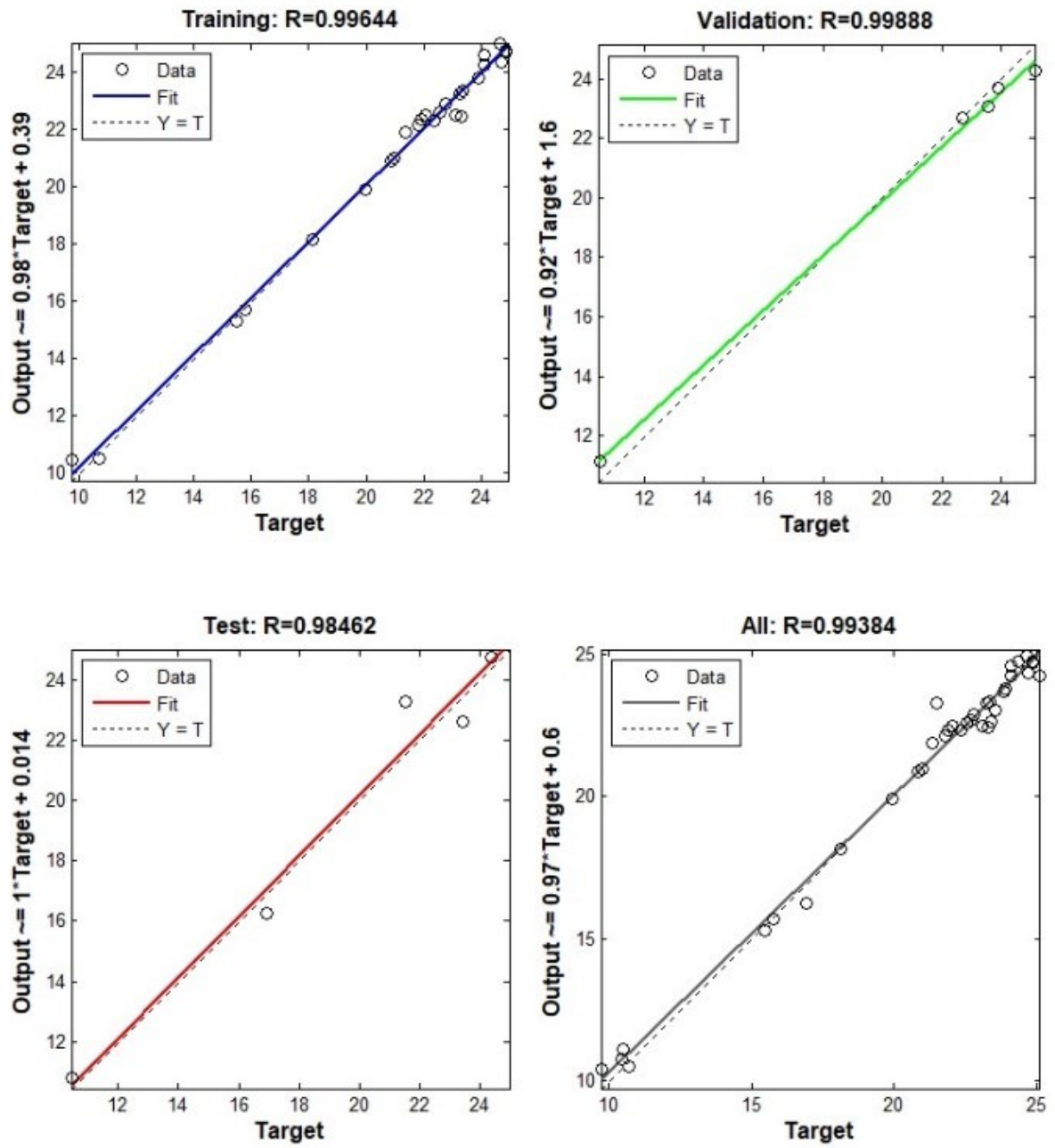

Figure 6. Overal R values of ANN model
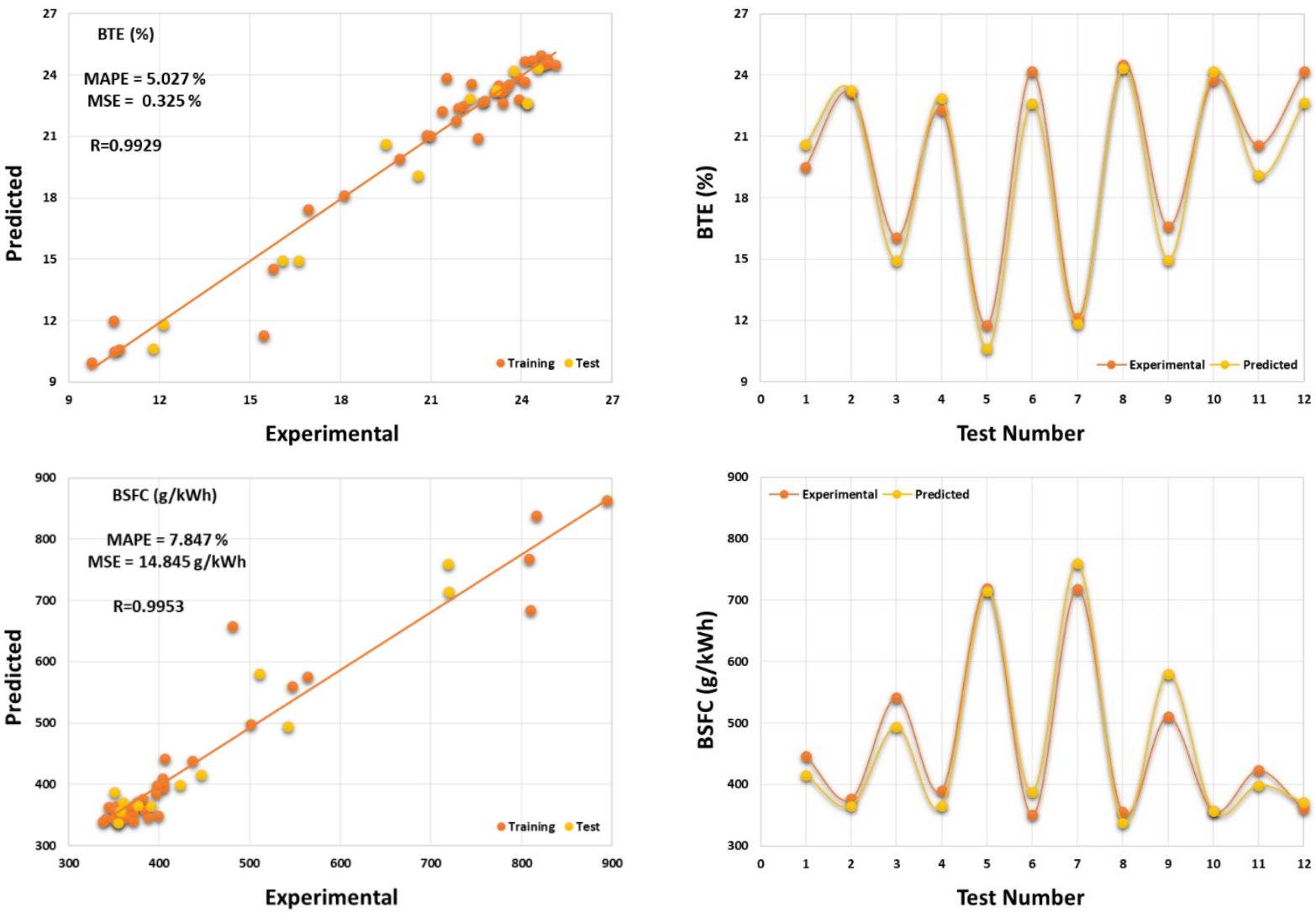

Figure 7. Comparison of experimental results and ANN results for BTE and BSFC 
Table 7. Confirmation of experimental and predicted results

\begin{tabular}{cccccc}
\hline $\begin{array}{c}\text { Fusel Oil } \\
\text { Ratio (\%) }\end{array}$ & $\begin{array}{c}\text { Load } \\
(\mathbf{W})\end{array}$ & $\mathbf{C R}$ & & $\begin{array}{c}\text { BTE } \\
\mathbf{( \% )}\end{array}$ & $\begin{array}{c}\text { BSFC } \\
(\mathbf{g} / \mathbf{k W h})\end{array}$ \\
\hline 20 & 3000 & 8 & Predicted & 19.957 & 436.575 \\
& & & Experimental & 19.919 & 439.042 \\
& & & Error (\%) & 0.189 & 0.565 \\
\hline 10 & \multirow{2}{*}{6000} & \multirow{2}{*}{9.12} & Predicted & 25.121 & 337.588 \\
& & & Experimental & 24.486 & 339.225 \\
& & & Error (\%) & 2.527 & 0.485 \\
\hline 10 & \multirow{2}{*}{4000} & \multirow{2}{*}{10.07} & Predicted & 23.375 & 362.812 \\
& & & Experimental & 22.656 & 345.550 \\
& & & Error (\%) & 3.077 & 4.758 \\
\hline
\end{tabular}

In order to verify the results obtained with the input parameter values estimated by using ANN, engine tests were performed with the same values and the results obtained are shown in Table 7 together with the ANN results and error rates. It is clearly understood from the table that there is an error of less than $5 \%$ between the estimation results and the test results. Thus, it is revealed that the estimation ability of ANN is within acceptable limits.

\section{Conclusion}

In present research, an ANN model has been established to estimate the performance parameters such as BTE and BSFC of a singlecylinder spark ignition engine using fusel oil/gasoline fuel mixtures. The test data required for the establish of the ANN model are two different fusel oil rates (10\% and $20 \%)$ of the single-cylinder spark ignition engine, three different CR values (8.00, 9.12 and 10.07), and eight different engine load values. It has been obtained from the data obtained by running $(1000,2000,3000,4000,5000,6000,7000$ and $8000 \mathrm{~W}) .75 \%$ of the experimental data were used for training of ANN and 25\% for testing ANN. For the created ANN model, fusel oil ratio, $\mathrm{CR}$ and engine load were chosen as the input parameter, while BTE and BSFC were determined as output responses. The optimum number of neurons was determined by choosing different numbers of neurons and the maximum $\mathrm{R}$ and minimum MSE and MAPE are obtained with a network that is a hidden layer with 10 neurons. Therefore, (3-10-2) topology is observed to be the ideal for predicting the inputoutput parameters wherein three neurons for input layer, ten neurons for hidden layer and two neurons for output layer. The main results obtained from this study are summarized below;
For all test fuels, BTE increased as the compression ratio increased from 8 to 9.12 and decreased again at the compression ratio of 10.07. In addition, it was observed that BTE increased with increasing fusel oil ratio. On the other hand, it is clearly seen that low lower calorific value of fusel oil causes BSFC to increase.

$\checkmark \quad \mathrm{R}$ values, which are an indicator of the estimation performance of ANN, were found as 0.9929 and 0.9953 for the estimation of BTE and BSFC values, respectively.

$\checkmark$ Results obtained by comparing ANN estimation results with experimental data for verification showed that there is less than 5\% error between ANN estimates and test data.

The results show that ANN can be utilized successfully to estimate the performance responses of a spark ignition engine filled by fusel oil / gasoline fuel mixtures. Based on the current study results, this research has shown to engine manufacturers and researchers that they can reach many experimental data with a smaller number of experiments, both saving time and reducing engineering efforts.

\section{References}

1. Biswal, A., Kale, R., Teja, G. R., Banerjee, S., Kolhe, P., Balusamy, S., "An experimental and kinetic modeling study of gasoline/lemon peel oil blends for PFI engine," Fuel, vol. 267, 2020.

2. S. Simsek, "Effects of biodiesel obtained from Canola, sefflower oils and waste oils on the engine performance and exhaust emissions," Fuel, vol. 265, pp. 117026, 2020.

3. Suiuay, C., Laloon, K., Katekaew, S., Senawong, K., Noisuwan, P., Sudajan, S., "Effect of gasoline-like fuel obtained from hard- 
resin of Yang (Dipterocarpus alatus) on single cylinder gasoline engine performance and exhaust emissions," Renew. Energy, vol. 153, pp. 634-645, 2020.

4. S. Uslu and M. B. Celik, "Prediction of engine emissions and performance with artificial neural networks in a single cylinder diesel engine using diethyl ether," Eng. Sci. Technol. an Int. J., pp. 0-7, 2018.

5. Masum, B. M., Masjuki, H.H., Kalam, M.A., Palash, S.M., Wakil, M.A., Imtenan,S., "Tailoring the key fuel properties using different alcohols (C2-C6) and their evaluation in gasoline engine," Energy Convers. Manag., vol. 88, pp. 382-390, 2014.

6. Solmaz, H., "A comparative study on the usage of fusel oil and reference fuels in an HCCI engine at different compression ratios," Fuel, vol. 273, p. 117775, 2020.

7. Santhosh, K., Kumar, G.N., Radheshyam, Sanjay, P.V., "Experimental analysis of performance and emission characteristics of CRDI diesel engine fueled with 1-pentanol/diesel blends with EGR technique," Fuel, vol. 267, 2020.

8. Cao, C., Zhang, Y., Zhang, X., Zou, J., Qi, F., Li, Y., Yang, J., "Experimental and kinetic modeling study on flow reactor pyrolysis of iso-pentanol: Understanding of iso-pentanol pyrolysis chemistry and fuel isomeric effects of pentanol," Fuel, vol. 257, p. 116039, 2019.

9. Simsek, S. and Ozdalyan B., "Improvements to the Composition of Fusel Oil and Analysis of the Effects of Fusel OilGasoline Blends on a Spark-Ignited (SI) Engine's Performance and Emissions," Energies, vol. 11, no. 3, p. 625, 2018.

10. Şimşek, S., Özdalyan, B., Saygın, H., "Improvement of the Properties of Sugar Factory Fusel Oil Waste and Investigation of its Effect on the Performance and Emissions of Spark Ignition Engine," BioResources, vol. 14, no. 1, pp. 440-452, 2019.

11. Uslu, S. and Celik, M. B., "Combustion and emission characteristics of isoamyl alcoholgasoline blends in spark ignition engine," Fuel, vol. 262, 2020.

12. H. Solmaz, "Combustion, performance and emission characteristics of fusel oil in a spark ignition engine," Fuel Process. Technol., vol. 133, pp. 20-28, 2015.

13. O. I. Awad et al., "Using fusel oil as a blend in gasoline to improve SI engine efficiencies: A comprehensive review," Renew. Sustain. Energy Rev., vol. 69, no. December 2016, pp. 1232-1242, 2017.

14. Simsek, S. and Uslu, S., "Experimental study of the performance and emissions characteristics of fusel oil/gasoline blends in spark ignited engine using response surface methodology," Fuel, vol. 277, p. 118182, 2020. 15. Şimşek, S., Saygın, H., Özdalyan, B., "Improvement of Fusel Oil Features and Effect of Its Use in Different Compression Ratios for an SI Engine on Performance and Emission," Energies, vol. 13, no. 7, p. 1824, 2020.

16. Simsek, S. and Uslu, S., "Determination of a diesel engine operating parameters powered with canola, safflower and waste vegetable oil based biodiesel combination using response surface methodology (RSM)," Fuel, vol. 270, 2020.

17. Aydın, M., Uslu, S., Çelik, M. B., "Performance and emission prediction of a compression ignition engine fueled with biodiesel-diesel blends: A combined application of ANN and RSM based optimization," Fuel, vol. 269, 2020.

18. S. Uslu and M. B. Celik, "Prediction of engine emissions and performance with artificial neural networks in a single cylinder diesel engine using diethyl ether," Eng. Sci. Technol. an Int. J., vol. 21, no. 6, 2018.

19. B. Ghobadian, H. Rahimi, A. M. Nikbakht, G. Najafi, and T. F. Yusaf, "Diesel engine performance and exhaust emission analysis using waste cooking biodiesel fuel with an artificial neural network," Renew. Energy, vol. 34, no. 4, pp. 976-982, 2009.

20. Taghavi, M., Gharehghani, A., Nejad, F. B. and Mirsalim, M., "Developing a model to predict the start of combustion in HCCI engine using ANN-GA approach," Energy Convers. Manag., vol. 195, pp. 57-69, 2019.

21. R. K. Mehra, H. Duan, S. Luo, A. Rao, and F. Ma, "Experimental And Artificial Neural Network (ANN) Study Of Hydrogen Enriched Compressed Natural Gas (HCNG) Engine Under Various Ignition Timings And Excess Air Ratios," Appl. Energy, vol. 228, pp. 736-754, 2018.

22. T. M. Kiani Deh Kiani, B. Ghobadian, A. M. Tavakoli, and G. N. Nikbakht, "Application of artificial neural networks for the 
prediction of performance and exhaust emissions in SI engine using ethanol- gasoline blends," Energy, vol. 35, pp. 65-69, 2010.

23. J.P. Holman, "Experimental techniques for engineers", 7nth ed., Tata McGraw Hill, New Delhi, 2004.

24. V. Yap, W. K., Ho, T. and Karri, "Exhaust emissions control and engine parameters optimization using artificial neural network virtual sensors for a hydrogen-powered vehicle," Int. J. Hydrogen Energy, vol. 37, no. 10, pp. 8704-8715, 2012.

25. R. Deb, M., Majumder, P., Majumder, A., Roy, S., Banerjee, "Application of artificial intelligence (AI) in characterization of the performance-emission profile of a single cylinder CI engine operating with hydrogen in dual fuel mode: An ANN approach with fuzzylogic based topology optimization," Int. J. Hydrogen Energy, vol. 41, no. 32, pp. 1433014350, 2016.

26. Bhowmik, S., Panua, R., Debroy, D., Paul, A., "Artificial Neural Network Prediction of Diesel Engine Performance and Emission Fueled With Diesel-Kerosene-Ethanol Blends: A Fuzzy-Based Optimization," J. Energy Resour. Technol., vol. 139, no. 4, 2017.

27. D. P. Javed, S., Murthy, Y.V.V.S., Baig, R. U., Rao, "Development of ANN model for prediction of performance and emission characteristics of hydrogen dual fueled diesel engine with Jatropha Methyl Ester biodiesel blends," J. Nat. Gas Sci. Eng., vol. 26, pp. 549557, 2015.

28. Renald, C. J. T. and Somasundaram, P., "Experimental Investigation on Attenuation of Emission with Optimized LPG Jet Induction in a Dual Fuel Diesel Engine and Prediction by ANN Model," Energy Procedia, vol. 14, pp. 1427-1438, 2012.

29. Salam, S. and Verma, T. N., "Appending empirical modelling to numerical solution for behaviour characterisation of microalgae biodiesel," Energy Convers. Manag., vol. 180, pp. 496-510, 2019.

30. G. Najafi, B. Ghobadian, T. Tavakoli, D. R. Buttsworth, T. F. Yusaf, and M. Faizollahnejad, "Performance and exhaust emissions of a gasoline engine with ethanol blended gasoline fuels using artificial neural network," Appl. Energy, vol. 86, no. 5, pp. 630639, 2009.
31. A. Calam, Y. İçingür, H. Solmaz, and H. Yamık, "A Comparison of Engine Performance and the Emission of Fusel Oil and Gasoline Mixtures at Different Ignition Timings", International Journal of Green Energy, vol. 12, no. 8, pp. 767-772, 2015.

32. E. Y1lmaz, "Investigation of the effects of diesel-fusel oil fuel blends on combustion, engine performance and exhaust emissions in a single cylinder compression ignition engine", Fuel, vol. 255, pp. 115741, 2019.

33. O. I. Awad, R. Mamat, T. K. Ibrahim, F. Y. Hagos, M. M. Noor, I. M. Yusri, and A. M. Leman, "Calorific value enhancement of fusel oil by moisture removal and its effect on the performance and combustion of a spark ignition engine", Energy Conversion and Management, vol. 137, pp. 86-96, 2017.

34. A. N. Abdalla, H. Tao, S. A. Bagaber, O. M. Ali, M. Kamil, X. Ma, and O. I. Awad, "Prediction of emissions and performance of a gasoline engine running with fusel oil-gasoline blends using response surface methodology", Fuel, vol. 253, pp. 1-14, 2019.

35. A. Calam, H. Solmaz, A. Uyumaz, S. Polat, E. Y1lmaz, Y. İçingür, "Investigation of usability of the fusel oil in a single cylinder spark ignition engine", Journal of The Energy Institute, vol. 88, no. 3, pp. 258-265, 2015. 